\title{
Embedded Master's Students Conduct Highly Relevant Research Using Industry as Their Laboratory
}

\author{
Kristin Falk and Gerrit Muller
}

\begin{abstract}
"If you think competency is expensive, have you tried incompetency? ... ") In addition to getting good and motivated students, the company also gets working knowledge of the subject systems engineering. The company also benefits from assignments along the way, and the thesis is aimed at current issues in business. We have much to learn from these students.
\end{abstract}

\author{
Willy Holdahl \\ HR Director of GKN Aerospace Norway \\ Industry collaborator in the USN Systems Engineering program
}

\begin{abstract}
This article analyzes participatory action research conducted by Systems Engineering master's students embedded fifty percent in industrial companies for three years. The resulting papers authored by these students identify challenges and effective practices suitable for knowledge transfer between industry and academia. The analysis covers 181 completed master's projects, with a detailed analysis of 40 papers that have been published in international conferences and journals. The publication rate of about $23 \%$ shows that these students contribute actively to the body of Systems Engineering knowledge. This study analyzes master's projects at three levels - industrial problem and drivers; Systems Engineering methods; and research method feasibility - and provides valuable lessons learned by applying the industry-as-laboratory approach. Embedding students in industry has resulted in publications that do not suffer from the main challenges of participatory research such as delays, repeatability, and only action and not research. These insights are valuable both for industry and for academia in future work to enhance innovations.
\end{abstract}

\section{Introduction}

Systems Engineering as a profession emerged from the telecommunications and space programs in the United States in the 1950s. Motivating this emergence was the need for these systems to be safe, reliable, robust, and able to handle unforeseen events. Practicing systems engineers wrote the earliest Systems Engineering literature (Chestnut, 1967; Goode \& Machol, 1957), but it took nearly 20 years before academia began to offer explicit Systems Engineering educational opportunities and to produce textbooks. The subsequent literature has dealt not only with technological topics but also with the corresponding impacts on organizations that produce these complex systems.
Thus, research on Systems Engineering is still an emerging field. One challenge is that Systems Engineering is context dependent: the practice is dependent on both the engineering domain as well as the organizations and its surroundings. Another challenge is that valuable tacit knowledge remains largely undocumented within the companies and industries. Specifically, research on Systems Engineering implementation and best practices within the oil and gas industry is scarce. This raises questions about how to make this knowledge explicit and how to best apply Systems Engineering in different settings.

Systems Engineering master's students at the University of South-Eastern Norway (USN; tinyurl.com/y2e6h6za) are 


\section{Embedded Master's Students Conduct Highly Relevant Research Using Industry as Their Laboratory Kristin Falk and Gerrit Muller}

working with these questions to evaluate the effectiveness of the Systems Engineering body of knowledge in practice. To facilitate this process, USN - in close cooperation with the industry - created a new study model: the Industry Master's Program. Students in this program are embedded in a company for three years, working as an engineer $50 \%$ of the time and studying during the other $50 \%$. During the last half year, they use the industry-aslaboratory concept (Potts, 1993) while they conduct their research. The industry partners provide an active study and research environment that benefits all parties.

This article analyzes the prior research performed by students in the Industry Master's Program at USN by answering the following questions:

1. How well does action research work for master's students?

2. How can industry and universities facilitate participatory action research performed by master's students within the field of Systems Engineering?

The central case examined in this study is thus the Systems Engineering master's projects in the Industry Master's Program. We analyze this case at two levels: 1) industrial application including Systems Engineering knowledge and 2) research methods with a focus on research methods and feasibility.

The remainder of this article is organized as follows. First, we provide some background on Systems Engineering pedagogy, the Industry Master's Program and projects, and the role of action research in those projects. This is followed by sections describing the research method and their results, analyzing various aspects of papers produced by students in the Industry Master's Program, including: industrial value, research methods, elements that assist or hinder the research, as well as experiences and recommendations. The article ends with a discussion and conclusions.

This article is aimed at business managers and engineers wanting to develop their companies by close and fruitful collaboration with academia, and researchers and students wanting to learn more about applying the industryas-laboratory concept. We often find that we have to explain the concept when we meet new university colleagues who are unaware of this type of teaching and action research and when we meet people from industry who are unaware of its existence. We also need to provide in-depth explanations to the students in our program and to their industrial mentors.
We, the two authors of this article, have supervised 104 of the 181 completed master's projects within this program between 2010 and 2017. We have supervised 28 Industry Master's students that have published papers in peer-reviewed conferences and conferences proceedings, which is $27 \%$ of the students we have supervised in that period of time. The first author, Kristin Falk, is an industrial expert in the domain of Systems Engineering within offshore oil and gas (Muller \& Falk, 2018), and the second author, Gerrit Muller, is an expert in the Systems Engineering research field (Muller 2009, 2013; Valerdi, Brown, \& Muller, 2010).

In this article, we draw on our research and experience to provide new insights and perspectives and to add to the literature in the field of action research and industry-university collaboration.

\section{Background}

\section{Systems Engineering pedagogy}

Systems Engineers typically work as engineering managers, systems architects, or project managers in projects that develop complex systems. These engineers often encounter situations where they need to influence stakeholders to select a suitable solution (McKinney \& Contractor, 2013). The field of System Engineering differs from other engineering disciplines as it covers a broad scope, it involves humans, it involves ill-defined problems with many unknowns, and it involves problems without a single unique best answer (Muller \& Bonnema, 2013).

The broad scope of Systems Engineering fits well with an experiential learning model, where the student learns more than theory. Theories from the sociocultural view (Vygotsky, 1978, 1986) on learning by doing and reflection are highly relevant to this discipline. Vygotsky advanced a view that knowledge and understanding were socially constructed through interactions with others. Lave and Wenger (1991) emphasized that learning is a participation in practice fellowship. This also relates to Kolb's (2014) learning cycle: experiencing, reflecting, generalizing, and applying.

Figure 1 illustrates the synergy between industry, teaching, and research within Systems Engineering. The industrial domain focuses on the actual systems under development. The practitioners (or engineers) in the industrial domain apply engineering methods to realize these systems. Engineering methods are what we teach at universities. Research should give objective validation and evidence for these methods. To validate 


\section{Embedded Master's Students Conduct Highly Relevant Research Using Industry \\ as Their Laboratory Kristin Falk and Gerrit Muller}

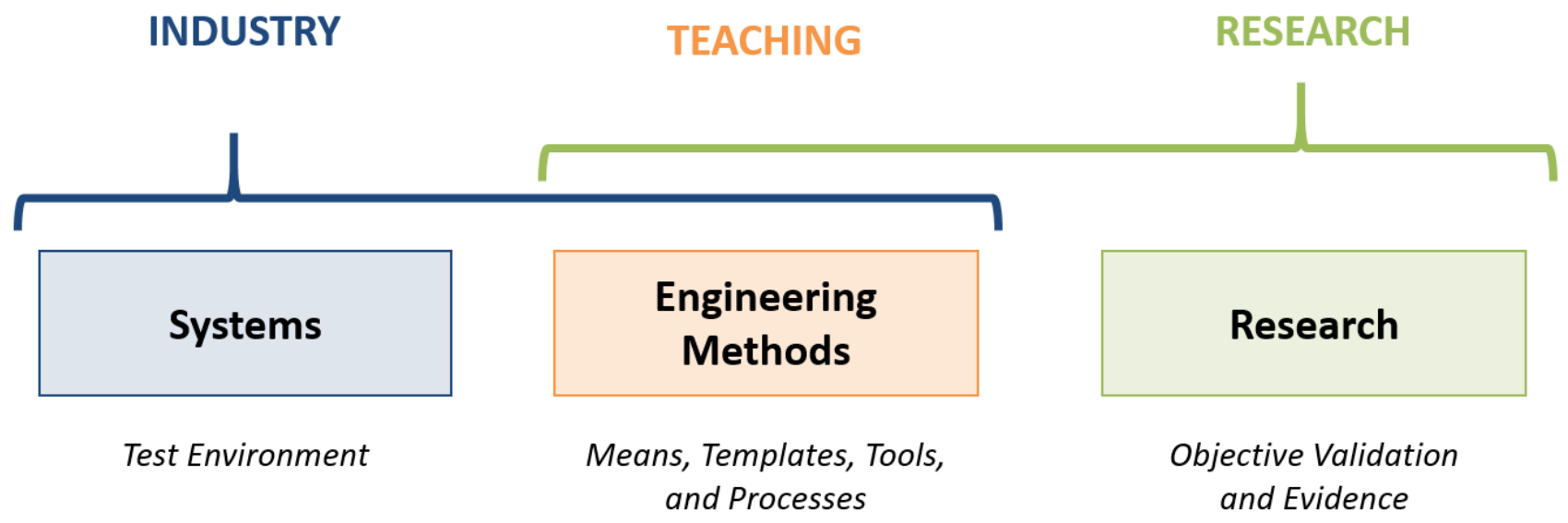

Figure 1. Industry, teaching, and academia synergy within the domain of Systems Engineering

the engineering methods during our research, we use the real-world systems as a test environment.

Garousi and colleagues (2016) presented (very) long lists of "best" and "worst" practices in industry-university collaboration. The best practices with the most references were:

- Run regular workshops and seminars.

- Base research on real-world problems.

- Ensure engagement and manage commitment.

- Be agile.

- Ensure that the research provides benefits to industry and solves the right problems.

As described in the next subsection, the Industry Master' model strives to support these practices.

\section{The Industry Master's model at USN}

In 1999, the Philips Research Department of Information and Software Technology and its group in Software Architectures were using Colin Potts' research model called "industry-as-laboratory". Potts (1993) observed that barely any research in software engineering transferred into practice. He hypothesized that most research focuses on the methods, techniques, tools, and concepts, without taking into account the practical context of using them. He promoted a research concept where researchers validate the research topics by applying them in practice.
In 2002, the Embedded Systems Institute (ESI; esi.nl) started a number of collaborative projects between academia and industry. The ESI staffed these projects, such as Boderc (redesign.esi.nl/boderc/), with a few research fellows, a significant number of PhDs, and some industry participants. These projects adopted the industry-as-laboratory research approach, scaling it up to a significant research effort. Muller and Heemels (2007) evaluated the research approach at the end of the Boderc project. Experiences with PhDs in the ESI period, around 2002, showed that it was quite challenging for PhD students to contribute within the industrial context. They continuously experienced opposing forces:

- The industrial problem, requiring pragmatic solutions quickly

- The academic environment, requiring depth and academic rigour

In 2006, the local university college in Kongsberg (now part of the University of South-Eastern Norway) established a new Industry Master's program in Systems Engineering. This program incorporates experiential learning as the pedagogic model for Systems Engineering through close cooperation between industry and academia. The industry offers paid part-time working positions to Systems Engineering students, which allow them to connect theory and practice to make this model work. Teachers and students share cases from their industrial experience as part of the courses. The university used the ESI experiences to model the master's projects. In retrospect, the working period before 


\section{Embedded Master's Students Conduct Highly Relevant Research Using Industry as Their Laboratory Kristin Falk and Gerrit Muller}

starting the master's project serves well to overcome some of the conflicts experienced in ESI.

The Industry Master's program at USN differs significantly from other master's studies in Engineering, at least in Norway, where students normally have very limited working experience. Some students do their final master's project thesis affiliated with a company but may struggle, as they need time to understand the context and help in defining relevant problems. Occasionally, students have relevant part-time jobs, industrial internships, or co-op placements between study, which afford them some of the same advantages as the USN master's students when doing industrial research.

The Industry Master's students go through a three-year course in reflective practice. According to the curriculum, the course should give the students knowledge of: reflection methods and learning cycle; knowledge of communication; frameworks for domain knowledge; academic writing; ability to reflect on work and education; and ability to develop themselves from a student into a professional employee. Muller (2015) documents how reflective practice is a core element in connecting theory and practice culminating in Industry Master's projects. As part of reflective practice, a program coordinator informs the students about the master's project at the very beginning of their study and guides them in their search for a topic through reflective practice workshops. At the end of the second study year, the students follow three workshops to select a topic, shape the master's project, and determine a research approach (indicated by the first three milestones in Figure 2). Three months before the start of the project, the coordinator assigns academic supervisors to students based on the topic. Students and their academic supervisors finalize the definition and research approach for each project before students begin to execute them.

The execution period of a master's project consists of a study load of 6 months of full-time effort (approximately 20 weeks) usually conducted in the final semester before graduation. When students are starting their master's project, they have been working at the company for two and a half years. By then, they know the company, the systems, the technology, the people, and the processes. During the first months of the master's project execution phase, the focus of the students is on the case and its industrial context. Students maintain regular contact with their academic supervisors, reflecting on the research itself. The fourth milestone indicates a workshop on academic writing, addressing the structure of the thesis and review of the research methods, among other topics.

During their master's projects, the students use the industry-as-laboratory approach, which is a sub-group of action research (Muller, 2013). The main triggers for the research should be "effective use of System Engineering methods in industrial practice." The idea is that action research enables students to understand and evaluate their respective company and its practices.

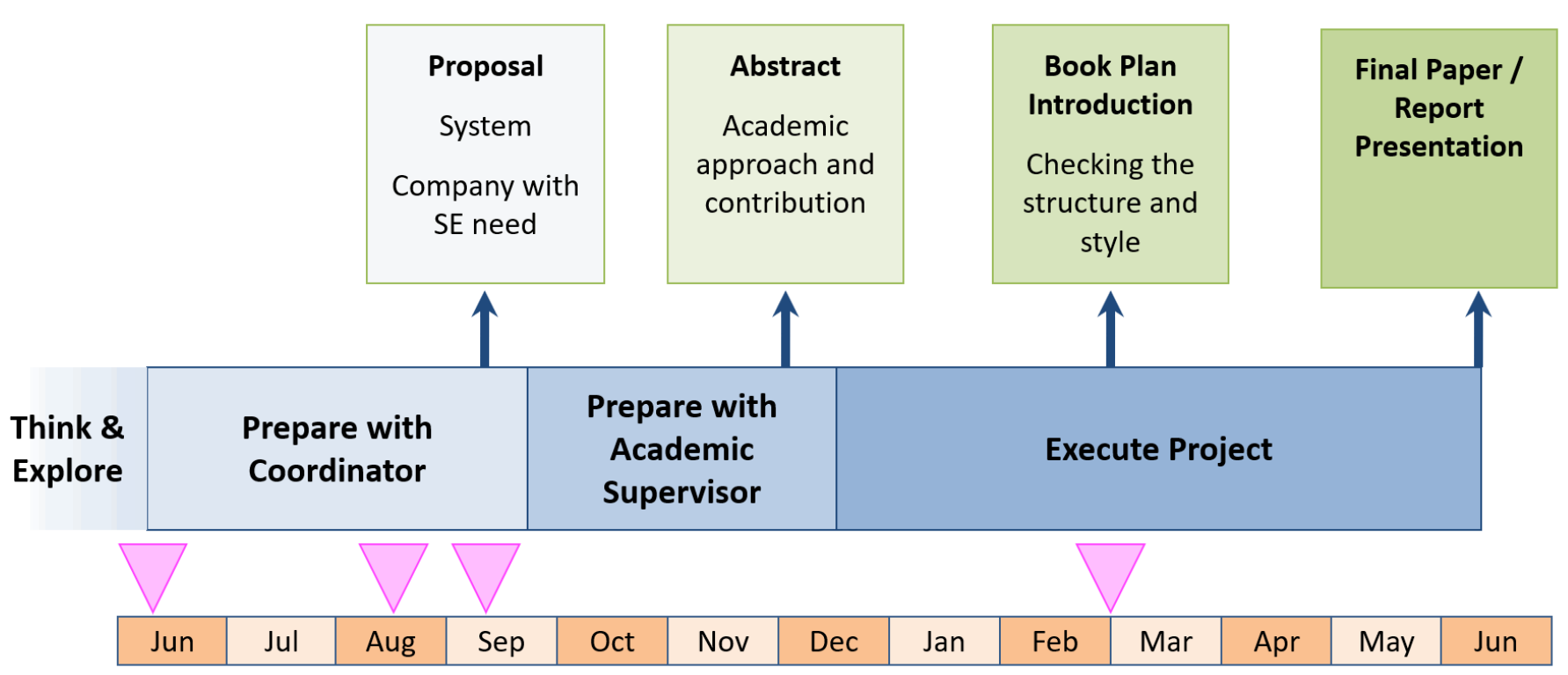

Figure 2. Master project preparation and execution phase (Muller, 2012) 


\section{Embedded Master's Students Conduct Highly Relevant Research Using Industry as Their Laboratory Kristin Falk and Gerrit Muller}

\section{Action research}

This article relates papers authored by the master's students to definitions and characteristics of action research as provided by O'Brien (2001):

\section{"Action research...aims to contribute both to the practical concerns of people in an immediate prob- lematic situation and to further the goals of social science simultaneously. Thus, there is a dual com- mitment in action research to study a system and concurrently to collaborate with members of the system in changing it in what is together regarded as a desirable direction. Accomplishing this twin goal requires the active collaboration of researcher and client, and thus it stresses the importance of co- learning as a primary aspect of the research pro- cess."}

Action research focuses on each of four phases - plan, act, observe, and reflect - and is conducted in iterations. Koshy (2005) provides a rather detailed description of action research and different methods. Tripp (2005) discusses different types of action research and claims that the researcher should be actively involved in the problem solving for it to be proper action research. Saunders and co-authors (2012) give a broad classification of action research. Interactive research has been described as "the idea of knowledge creation through cooperation between researchers and practitioners" by Ellström (2007). Research-Methodology.net (2018) listed three advantages of action research:

1. "High level of practical relevance of the business research"

2. Can be used with quantitative, as well as, qualitative data"

3. Possibility to gain in-depth knowledge about the problem"

They also listed three disadvantages:

1. "Difficulties in distinguishing between action and research and ensure the application of both"

2. Delays in completion of action research due to a wide range of reasons are not rare occurrences"

3. Lack of repeatability and rigor"
Beard and Wilson (2006) investigated how learning equals change, and how people learn and change. Reflective practice is very important in this process: "There are four distinct phases, which involve a concrete experience, thinking about the experience, generalizing and conceptualizing about the experience, and finally applying these ideas and thoughts to new situations. ... In the third stage, we make links and connections to our previous experience and knowledge. Without these links the experience may have little value in learning." Beard and Wilson (2006). This is similar to Kolb's learning cycle (experiencing, reflecting, generalizing, and applying) as applied in reflective practice for Systems Engineering students at USN (Muller, 2015).

Engaged scholarship is based on the management profession and can be performed in many ways; also in the form of action research. Van de Ven (2007) stated that, if we ground our research questions in practice and involve practitioners in problem formulation, theory building, research design, and problem solving, then management scholarship will flourish and the management profession will benefit. Furthermore, he argued that a deeper understanding of communicating knowledge across boundaries and a more engaged relationship between the researcher and their audience are needed if research findings are to have an impact in advancing science and practice. "It is one thing to write a research paper, and quite another to transfer, interpret, and implement study findings at the communication boundaries of both scientific and practitioner communities." (Van de Ven, 2007).

\section{Method}

The foundation of this research is a structural review of 40 papers published from Industry Master's projects. By published, we mean that the paper has been through peer review and published as a full paper. Thirty-three of the student papers were published in proceedings of the International Council on Systems Engineering (INCOSE) Annual International Symposium. This is the largest worldwide annual gathering of people who do Systems Engineering. The symposium attracts an international mix of professionals at all levels and includes practitioners in government and industry, as well as educators and researchers. The remaining papers were published in in journals and conference proceedings, as shown in Table 1. 


\section{Embedded Master's Students Conduct Highly Relevant Research Using Industry as Their Laboratory Kristin Falk and Gerrit Muller}

Table 1. Publication channels for published master's papers

\begin{tabular}{ll}
\hline Publication Channel & Type \\
\hline INCOSE's Annual International Symposium & Conference Proceedings \\
\hline International Journal of Information and Communication Engineering & Journal \\
\hline Sustainability & Journal \\
\hline International Conference on Industrial Engineering and Engineering Management & Conference Proceedings \\
\hline European Systems Engineering Conference (EUSEC) & Conference Proceedings \\
\hline Conference on Systems Engineering Research (CSER) & Journal / Proceedings \\
\hline
\end{tabular}

Figure 3 shows the flow of the research. The background for the papers stems from the Industry Master's model and the literature on action research. After a methodical review of the papers, the results are analyzed and discussed according to the following dimensions:

- Industrial value of the Systems Engineering methods and tools
- Research method related to theory and definition of action research

- Elements assisting or hindering the research

- Experiences and lessons learned (based on all completed master's projects, not just those resulting in publications)

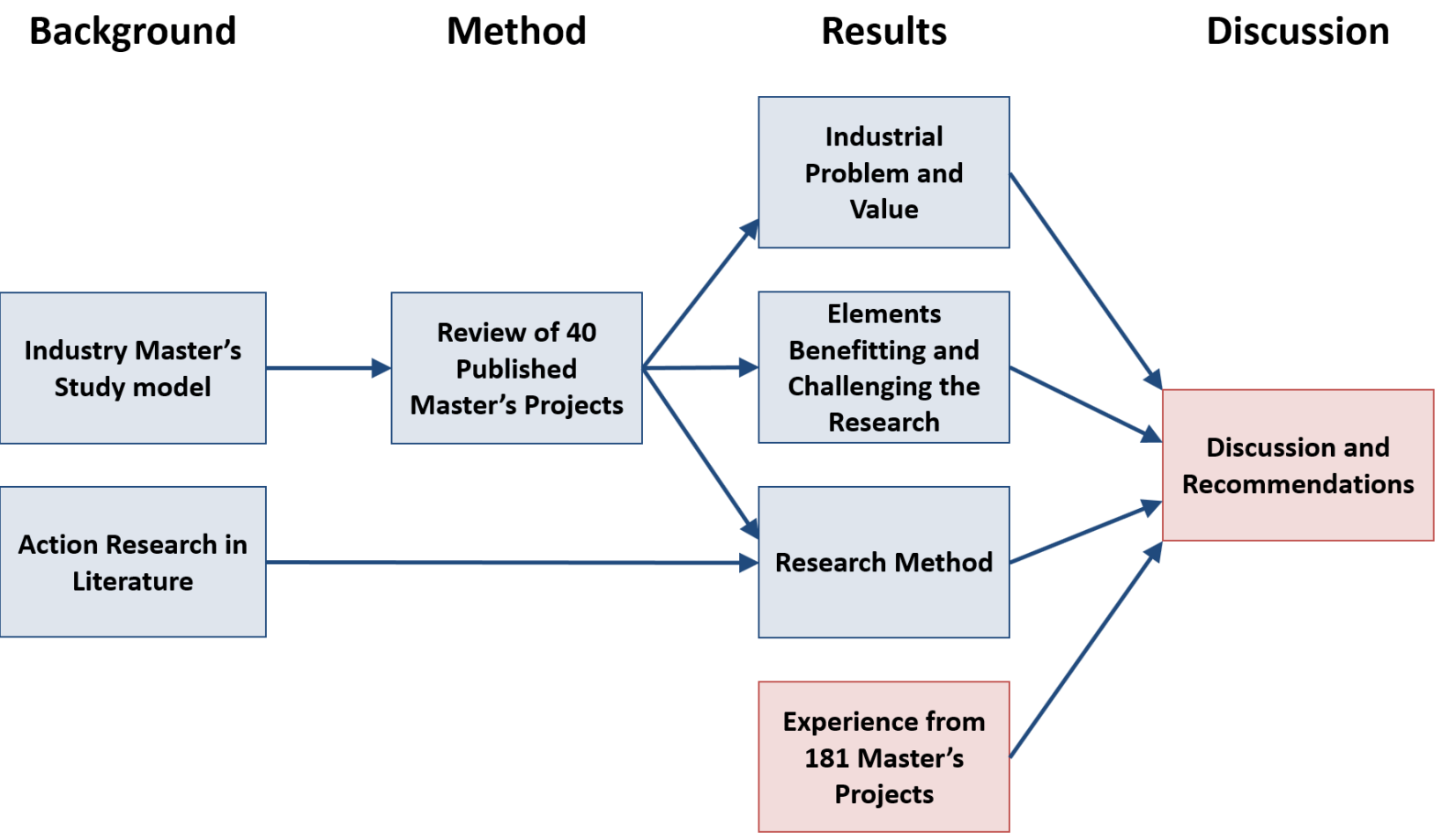

Figure 3. Research flow 


\section{Embedded Master's Students Conduct Highly Relevant Research Using Industry as Their Laboratory Kristin Falk and Gerrit Muller}

The underlying problem is identified for each paper and then is oriented according to our current research roadmap. The roadmap was derived from a number of meetings and workshops with industrial partners and contains the following industrial research triggers: autonomous systems, digital transformation, continuous innovation, effective manufacturing, connected world, and systems of systems. Benefits or qualities, defined by the research roadmap, are effectiveness in development, trustworthiness, human suitability, and changeability. In the early days, "reliability in harsh environments" and "innovation/evolvability" were guiding concepts or terms. Information about the main result and main conclusion was extracted from each paper. Appendix 1 lists the papers published by the master's students as analyzed in this work.

For each paper, we compared the research methods used to definitions and characteristics of action research, and we classified them on a scale from one to five. We also wrote down specific elements that could hinder or assist the effectiveness of action research. In addition, we examined whether the students had used the different phases of action research (i.e., plan, act, observe, and reflect) and whether the students used qualitative or quantitative research methods. Finally, we identified whether the students made use of interviews, workshops, literature, or historical data to support their research.

After scanning the papers to find elements assisting or hindering the effectiveness of action research, only $80 \%$ of the master papers clearly met the definition of action research (based on researchers understanding of paper). These were papers with a positive or neutral answer to both of the criteria: "The research aims at changing the practice" and "The research involves colearning (a group of practitioners)". Based on our experience and our systematic review of the published papers, we developed an in-depth discussion and recommendations related to how master's students can perform action research within industry.

When reading the papers, we also analyzed their readability and recorded their citation count from Google Scholar. By December 1, 2018, five papers had a Google Scholar citation count of seven or higher, and more than half of the papers had no citations. Only one of the papers from the population of 40 was identified as "very difficult" to examine, and four were "difficult" to analyze. In two of these five papers, the researchers struggled to see the practical relevance, whereas the other three contained insufficient details of the research method. Information related to industrial value was often hidden within the papers. The researchers had to make interpretations based on 20 years of industrial experience from innovation and management within the energy sector. The Systems Engineering tools, methods, and processes were the most easily available items to discover in our analysis, because there were typically mentioned in the abstract, body, and conclusion sections.

\section{Results}

Students in the Industry Master's program work in various industries. Figure 4 displays the industry affiliation of all 309 students enrolled in the program between 2006 and 2017. Of these, 181 students have graduated in the same period, and 42 of them have had their papers published.

Figure 5 displays the industry affiliation of the 40 published master's papers that we analyzed in detail. The energy industry has, by far, the most papers, representing almost half of the papers. The two other industries with more than one paper are manufacturing and maritime. Defense, maritime, manufacturing, consultancy, and automotive are the other main industries that have employed the students.

\section{Industrial value of the published papers}

Supervisors of master's projects ask the students to focus on a specific, relevant, and important problem in the company where they work. For example, they ask: "What makes the boss worried?" Thus, the immediate industrial needs rather than the longer-term drivers determine most, but not all the master project topics. Figure 6 shows the industry problems that the published papers have identified. Cost and then quality are the most common problems. In addition, at least five students have investigated problems related to time, risk and safety, and customer satisfaction.

As shown in Figure 4, 23 of the published master's project were within a single industry: energy. These papers focused on offshore energy, primarily subsea oil and gas. In this industry, there was a sudden drop in oil price in 2015, followed by an intense focus on cost and time. Seven out of eight publications from the 2016 and 2017 cohorts mention cost/time as the main problem. On the other hand, only one of the five publications from 2010 and 2011 mentions cost or time as a primary issue. Our findings give a strong indication that the papers deal 


\section{Embedded Master's Students Conduct Highly Relevant Research Using Industry as Their Laboratory Kristin Falk and Gerrit Muller}

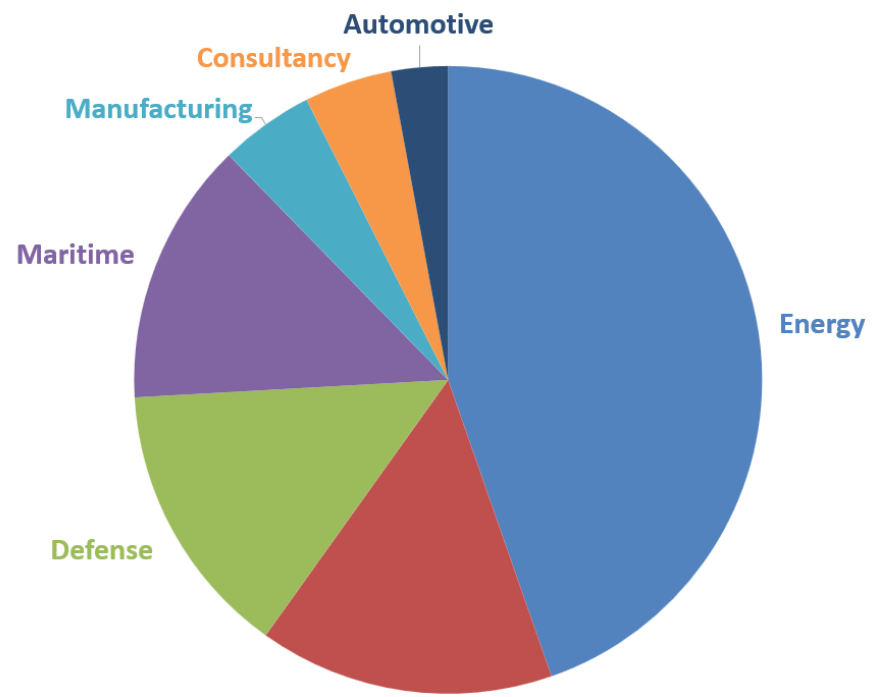

Miscellaneous

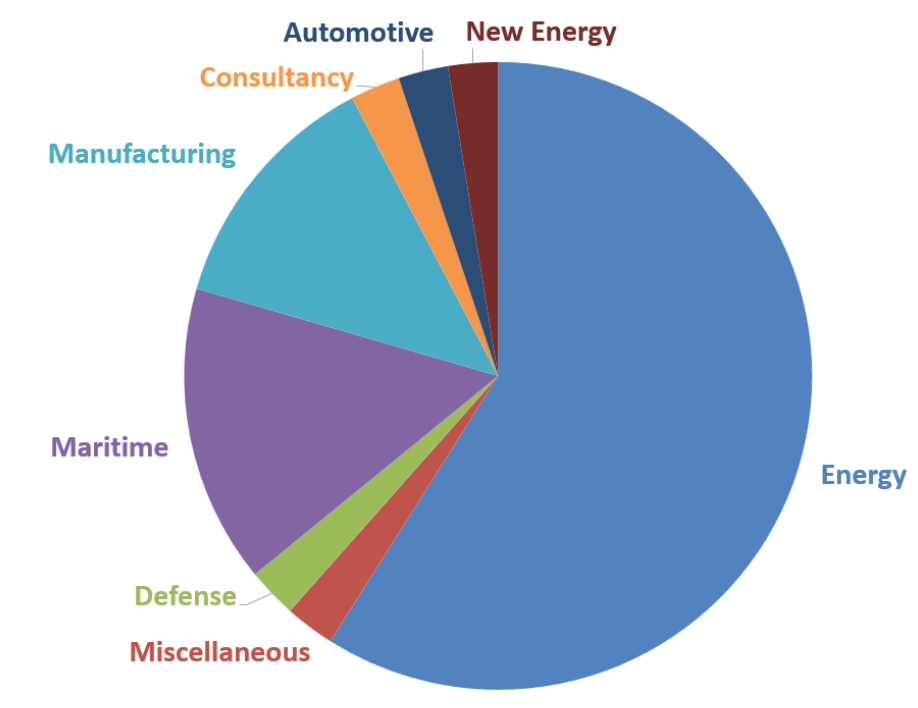

Figure 5. Industry affiliation of the 40 papers published by master's students between 2006 and 2017
Figure 4. Industry affiliation of all students enrolled in the Industry Master's program between 2006 and 2017

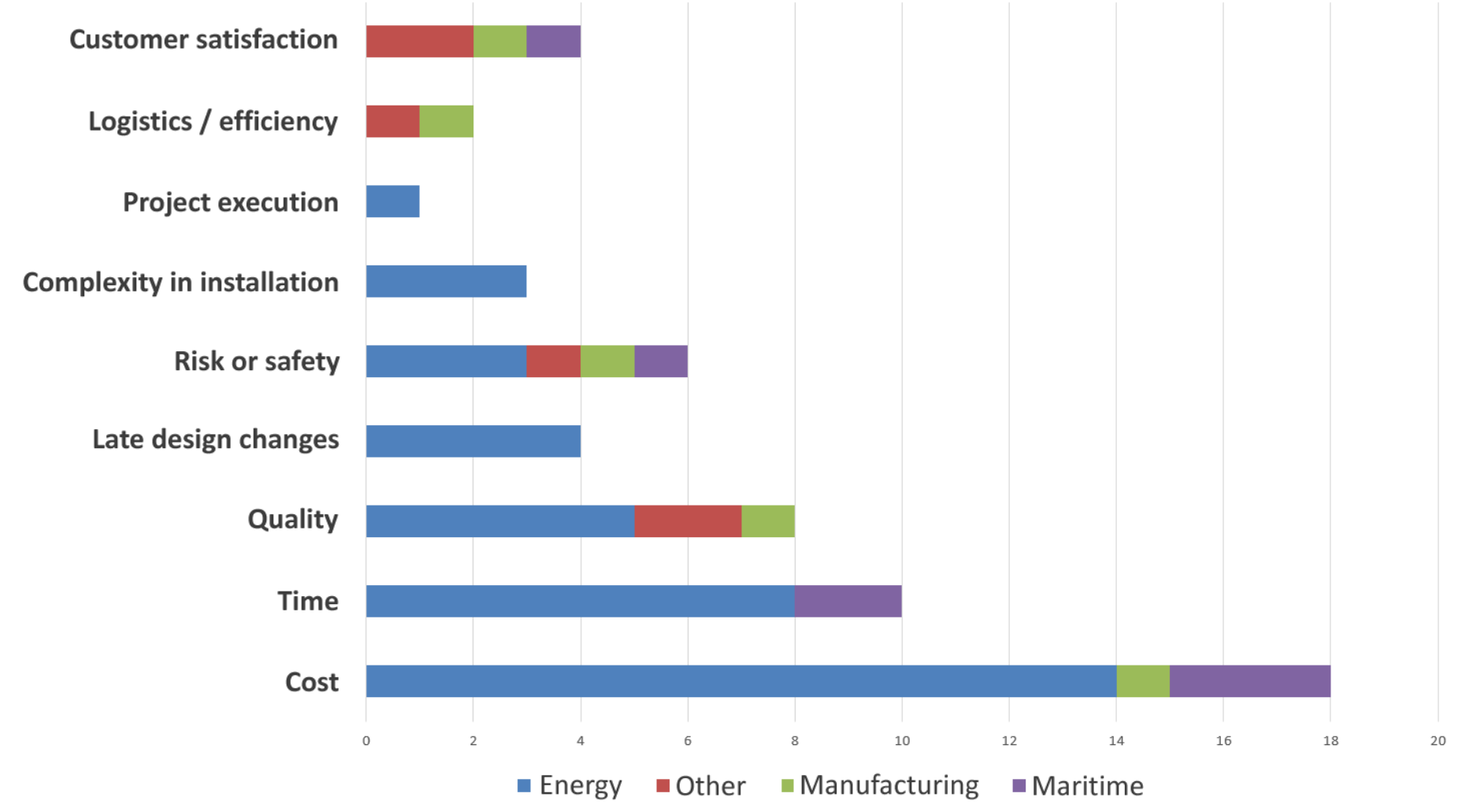

Figure 6. Problems that the published master's papers were attempting to solve, sorted by the different industries. One paper can address more than one problem. 


\section{Embedded Master's Students Conduct Highly Relevant Research Using Industry as Their Laboratory Kristin Falk and Gerrit Muller}

with real-world issues and real cases important to the industrial companies where the students are working during their entire master's studies.

Table 2 lists the most prominent key triggers of the research and qualities (benefits) of using the Systems Engineering methods and tools. Even though many papers were written prior to our current research roadmap, there is still a strong link between the papers and roadmap. Systems of Systems and Innovation are the most common research triggers. Digitalization and Autonomy are recent triggers. When it comes to qualities, effectiveness in development and trustworthiness are the most common. This finding originates from the former research agenda focusing on trustworthiness and effective methods.

Table 3 lists results and conclusions presented by the five papers with the highest Google Scholar citation counts as of December 12, 2018. The results and conclusions in Table 3 are rather tangible and easy to grasp. This is not
Table 2. Analysis of 23 energy papers with respect to key triggers for the research and benefits of using the Systems Engineering methods and tools

\begin{tabular}{lclc}
\hline Research Triggers & & \multicolumn{2}{l}{ Qualities (Benefits) } \\
\hline Systems of systems & 13 & $\begin{array}{l}\text { Effectiveness in } \\
\text { development }\end{array}$ & 10 \\
\hline Innovation & 6 & Trustworthiness & 9 \\
\hline $\begin{array}{l}\text { Digitalization and } \\
\text { autonomy }\end{array}$ & 3 & Human suitability & 2 \\
\hline $\begin{array}{l}\text { Efficiency in the } \\
\text { organization }\end{array}$ & 1 & Changeability & 2 \\
\hline
\end{tabular}

Table 3. Results and conclusions for the five papers with the highest Google Scholar citation count

\begin{tabular}{clll}
\hline Citations & Main Topic & Results (extracted from Abstract) & Conclusions (extracted) \\
\hline 20 & $\begin{array}{l}\text { Needs } \\
\text { Analysis }\end{array}$ & $\begin{array}{l}\text { Early capturing of customer needs and user } \\
\text { requirements could give "92\% reduction in } \\
\text { cost of late design changes" }\end{array}$ & $\begin{array}{l}\text { "Proper use of systems engineering ensures a } \\
\text { minimal amount of late design changes. The most } \\
\text { important systems engineering process in such a } \\
\text { context, is the capturing of customer needs and } \\
\text { definition of user requirements." }\end{array}$ \\
\hline
\end{tabular}

\begin{tabular}{|c|c|c|c|}
\hline 8 & $\begin{array}{l}\text { Concept } \\
\text { Modelling }\end{array}$ & $\begin{array}{l}\text { “...presents impact factors the architect can } \\
\text { use to increase a model's ability to assist } \\
\text { communication.” }\end{array}$ & $\begin{array}{l}\text { “...balancing and utilizing the right quantity of these } \\
\text { factors increase modeling value." }\end{array}$ \\
\hline 8 & $\begin{array}{l}\text { Concept } \\
\text { Selection }\end{array}$ & $\begin{array}{l}\text { "The application of Pugh Matrix in these } \\
\text { cases resulted in exploring more and farther } \\
\text { reaching alternate design than in the } \\
\text { normal practice." }\end{array}$ & $\begin{array}{l}\text { “...managers and engineers tend to skip the concept } \\
\text { phase and prefer to jump into a realization. The } \\
\text { perception is that Concept Selection is time } \\
\text { consuming; spending time on it cannot be afforded." }\end{array}$ \\
\hline 7 & A3AO & $\begin{array}{l}\text { "Using the A3 Dynamic Architecture } \\
\text { stakeholders were able to focus during } \\
\text { validation on one state at one time rather } \\
\text { than all the states combined." }\end{array}$ & $\begin{array}{l}\text { "Dynamic A3 Architecture can ease internal and } \\
\text { cross boundary communication, train new } \\
\text { employees, facilitate knowledge capture, and share } \\
\text { common understanding of the "system of interest". } \\
\text { A functional sequence diagram, which is a hybrid of } \\
\text { a state and functional diagram, can assist in early } \\
\text { validation of process applications." }\end{array}$ \\
\hline 7 & $\begin{array}{l}\text { Concept } \\
\text { Selection }\end{array}$ & $\begin{array}{l}\text { "The application of the Pugh Matrix in these } \\
\text { studies showed that if applied on the correct } \\
\text { level of detail as part of the concept } \\
\text { selection process, it is a powerful tool." }\end{array}$ & $\begin{array}{l}\text { "The involved engineers readily adopted the Pugh } \\
\text { matrix and they intend to continue using it, mainly } \\
\text { due to its ability to force structural thinking in } \\
\text { complex systems." }\end{array}$ \\
\hline
\end{tabular}




\section{Embedded Master's Students Conduct Highly Relevant Research Using Industry as Their Laboratory Kristin Falk and Gerrit Muller}

the case for the majority of the papers. Most of the papers concluded with more vague statements typically saying that the method or tool worked as intended, and was appreciated.

\section{Research method applied in the published papers}

All papers, except for one, made active use of qualitative research methods. Thirty percent also used quantitative research methods. About $80 \%$ of master's students used interviews or questionnaires. Some of them also held workshops. Interviews, questionnaires, and workshops were used to explore and gain deep understanding. They were also useful to validate the results. Thirty-five percent of the papers did not display a clear use of former literature as a part of the research. At least thirty percent used historical data actively, including data collected from former projects

About fifty percent of the papers were clearly iterative in their research method. We do assume that this was the case for others, but this was not explicitly stated in those papers. The "plan, act, observe, and reflect" procedures were used by about $75 \%$ of the papers, although some used only part of this reflective cycle.
As an example, Nilsen and co-authors (2018) made active use of the student's experience as an interface manager as a "substitute" for the plan and act phases. His observations had been ongoing during the previous three years while he was an employee and interface manager. He used these observations to provide the relevant data and discuss the relevant subjects. In addition, he used recordings from the prior six years and was able to perform a quantitative study combined with the qualitative in-depth analysis.

Figure 6 shows how the 40 papers align with the different characteristics of action research presented in the background section. The histogram indicates that most of the master's students were actively involved in problem solving, even though most of the papers are somewhat weak on repeatability and rigour and 11 displayed no repeatability at all. Even so, 14 of 40 papers displayed high repeatability and rigour. According to the literature, one of the characteristics of action research is that it often suffers from delays. Our results, presented in Figure 7 , are not conclusive on this point. For $50 \%$ of the papers, the students did not mention any delays. Only five of the papers indicate that they suffer
The author is actively involved in problem solving

The task displays repeatability and rigour

Action research completed without delays

Distinguishes between action and research, ensuring application of both

Researcher gains in-depth knowledge about the problem

High level of practical relevance of the research

The research involves co-learning (a group of practitioners)

The research aims at changing the practice
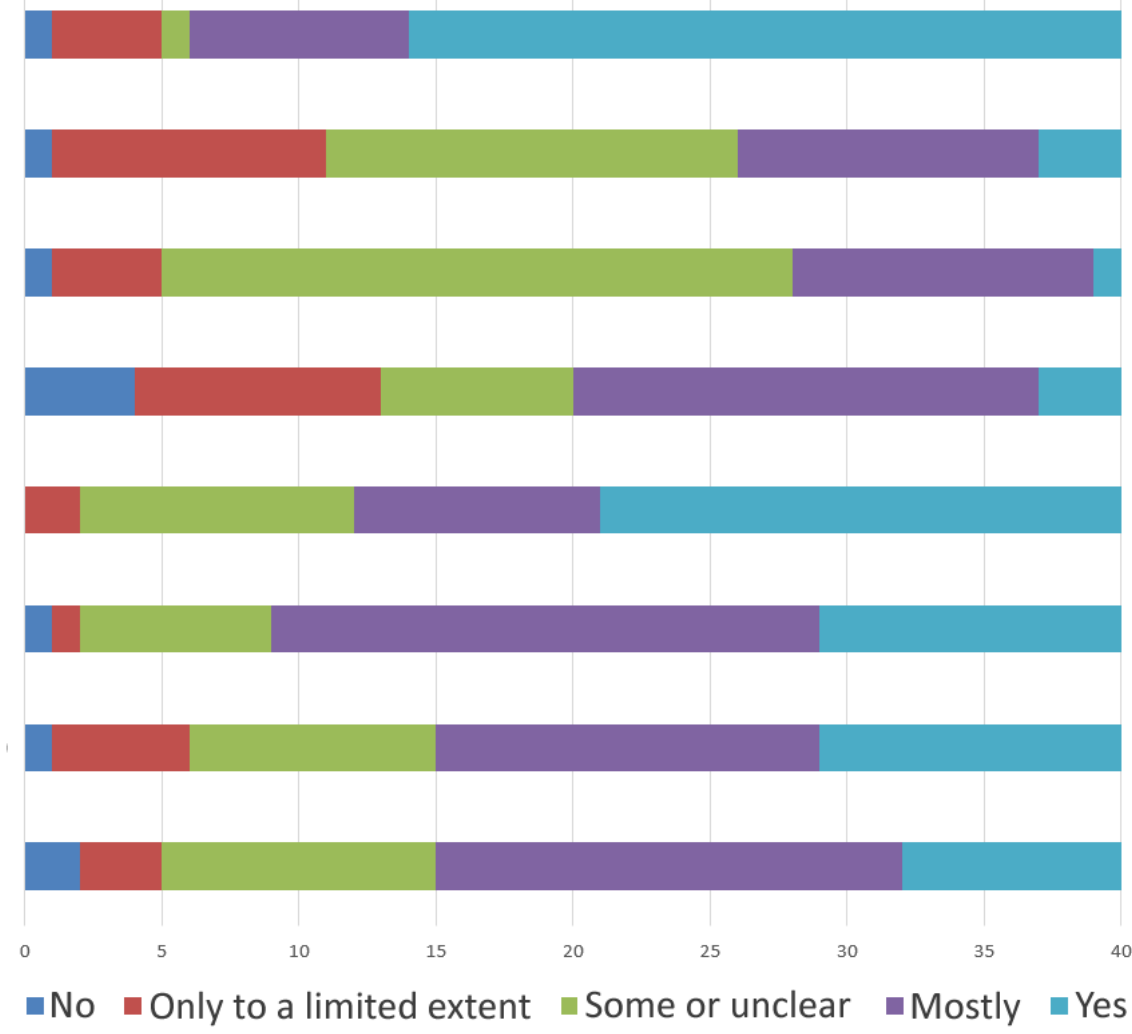

Figure 7. Histogram illustrating the extent to which the research methods in the published papers corresponded to the characteristics of action research 


\section{Embedded Master's Students Conduct Highly Relevant Research Using Industry as Their Laboratory Kristin Falk and Gerrit Muller}

from delay during their research execution, while 14 of the papers gave indications that delays were not a problem. According to our experience, the Industry Master's students are normally not delayed in completing their master's projects. However, we do see that some students need to change their research focus due to delays with products or projects that they had planned to research.

Distinguishing action and research is challenging for the master's students. Yet, only $20 \%$ of the published papers display clear difficulties in distinguishing between action and research, while $50 \%$ of the papers showed evidence of the application of both action and research. Also, our findings indicate that the students did seem to gain in-depth knowledge about the problem they were solving. The question related to the practical relevance was difficult for us to answer based on the papers alone. In general, we know from experience that the industry and academic supervisors are guiding the master's students toward relevant problems.

\section{Elements assisting or hindering the research}

Elements that seem to be hindering the effectiveness of action research include lack of communication and time, and lack of reflections. Notably, the employees in the industrial company prioritized productivity and did not want to "waste time". Some of them were said to be "Not willing to collaborate". Another statement from one of the papers was that "Personnel were not on board early enough" and others claimed that the communication around the research was ineffective or insufficient for the collaborating organization. Two of the papers mentioned the "meeting structure" as an issue. For example, one said: "When having interviews with three or more people we got off track easily, discussions around technical-, or organizational issues appeared." Other papers mentioned "limited time", "delayed industrial project", and "slow project progress and hard to get data due to confidentiality". One student reflected on the fact that he worked in a "single small project" as a limitation to his research. A few of the papers contain no or limited reflections and discussion.

Elements assisting the effectiveness of action research were strongly related to the students having worked for years in the company, but also "proper use of Systems Engineering and research methods." The papers revealed that the fact that the master's students "worked in a company" with "real projects, cases and problems" and with "access to stakeholders" as clear strengths in the research. This made them "very well involved with the subject". It is obvious from several of the papers that the students had been "actively involved for several years with the topic". One paper indicated that they had "very good support of the organization" where they performed their daily work. They often worked in "integrated teams". One paper mentioned the "team using the tool for some months". Another paper claimed that "Meetings with more than one stakeholder can also be beneficial, with cross fertilization, and creation of shared insight." Other elements that strengthened the research were selecting the "appropriate type of models" from Systems Engineering to solve the problem. Active use of "iterations" made the research more valuable as did "extensive use of questionnaires". Some of the strongest papers combined qualitative work with "quantification" and came out with quantified results.

\section{Further experiences and recommendations}

In our experience, it is crucial that the university understands and respects the industrial setting. At USN, we do this by hiring teachers with an industrial background. The supervisors at the university actively guide the students through their master's projects and encourage them to reflect on the subject of their research prior to starting it.

The majority of the master's project papers are not available in the public domain. There are a number of reasons for this, including insufficient quality and confidential content. In a selection of six unpublished papers, supervised by the main investigator, four of these projects were clearly participatory research containing results worth publishing. On the other hand, these papers contained confidential company information and would have needed significant re-writing to be cleared for publication. The remaining two papers suffered from having a simplistic problem and a simplistic solution. In both these latter two cases, the students spent most of their time learning new things on their own. Furthermore, both of these students were working in an industry focusing on downsizing instead of encouraging master's projects.

Supervision of the students is a continuous balancing act between encouraging students to be responsible (e.g., making it the students' responsibility to contact supervisors) and keeping their finger on the pulse of their students' work (e.g., supervisors "pinging" students that stay silent). A good model is to advise students to present and discuss content with their company supervisors bi-weekly, with a copy being sent to the academic supervisor. For example, the academic supervisor would make contact, or "ping" the student, 


\section{Embedded Master's Students Conduct Highly Relevant Research Using Industry as Their Laboratory Kristin Falk and Gerrit Muller}

if the period between contact gets longer than two weeks. Without this regime, we see that students too easily may fall in the trap of solving urgent problems at their companies that may not relate to their research.

Discussion of the content (i.e., What did they do? What was the impact?) is essential to keep the students on track. Simply submitting progress reports can easily hide a lack of real progress or progress that is actually in the wrong direction. The research period is quite limited (only 4 months, effectively). Frequently, the project scope, goal, and some research questions change due to insights gained along the way. Adapting the project to new insights is essential, but it creates uncertainty for the researchers and most stakeholders. However, ignoring new insights is often worse. The supervisors have to guide these adaptations and make sure that the project's line of reasoning keeps focused. They must also ensure that the project scope will fit the schedule and is appropriate for the level of study.

We advise the students to spend about two months out of the six analyzing and reporting their research. There is often too little time set aside for actual writing. As an example, a clever student worked in a project designing a new subsea system. The innovators loved the visual architecting tool he had developed and used it iteratively. The student was busy supporting the innovation to the end. As a result, his written master project report does not contain his new methods, nor does it reflect research that the student actually performed.

In all cases, the final paper has to present the findings in a clear concise top-down way. Hence, changes in the research during the execution should not be reported chronologically. Rather, the paper needs to explain how the project achieves the results. Any adaptations to the research approach are part of the research method, and the researcher may explain the adaptations in a reflection. Example of such change in direction is that the researcher discovers that analysis of the status quo takes so much time or that planned interventions are not feasible within the timescale of the project. However, the analysis of the status quo may still generate significant publishable value. An example of the value of status quo is Tranøy (2014), who did not validate his suggested improvements, but still has by far the highest Google Scholar citation count of all the industry master's student papers.

Finally, we found two recurring patterns in the last part of the execution project, the so-called U-turn and Z-turn:
- The U-turn is the effect that students start writing a chronological report. They have to make a mental Uturn to describe their lessons learned in a top-down fashion. That is quite a challenge because they have been embedded so much in the daily chaos of the industrial context.

- The Z-turn is the previous effect, where students discover, while U-turning, that they lost the research while being embedded: they did not collect sufficient data and observations to reach a proper evaluation. Hence, they need to make another swift repair action to collect evaluation data. This pattern typically appears despite regular advice from the students' coordinators and academic supervisors. A counter-measure to avoid a Zturn is to ask students for early initial evaluations.

\section{Discussion}

We have investigated how well action research works for master's students, and how industry and universities can facilitate participatory action research. We experience that the students improve the methods, learn from practice, and test the methods in a real environment. The article validates theory on action research, it presents an experimental learning model, and it analyzes an extensive list of papers validating Systems Engineering best practice. In addition, the article contributes by connecting theory on research and Systems Engineering to teaching and engineering practices.

The Industry Master's model at USN is completely dependent on collaboration between industry and academia. This is the case both for education and for research, as we have seen in this article. The model in Figure 1, which is designed to create synergies between industry, teaching, and academia within the domain of Systems Engineering, illustrates the ecosystem. This model supports the points of Garousi and colleagues (2016) with respect to "best practices" in industry-university collaboration. Reformulating these points to our context, we propose the following best practices:

1. Define real-world problems.

2. Provide benefits to industry and solve the right problems.

3. Manage engagement and commitment through the students and their work.

4. Be flexible and professional. 


\section{Embedded Master's Students Conduct Highly Relevant Research Using Industry as Their Laboratory Kristin Falk and Gerrit Muller}

5. Engage in workshops and seminars through courses and interactions with alumni.

Figure 6 presented the main findings from our structured literature review by relating the reviewed papers to theory on action research. A deeper analysis of the papers displayed that elements that seem to be hindering the effectiveness of action research include lack of communication and time, and lack of reflections. Elements assisting the effectiveness of action research were strongly related to the students having worked for years in the researching company, but also "proper use of Systems Engineering and research methods".

We offer the following recommendations for facilitating participatory action research using the industry-aslaboratory approach:

1. Define a research problem that is of high importance to the company. This makes the research relevant and significant with a high level of practical relevance. This is also supported by theory in Van de Ven (2007). Industry-as-laboratory has much in common with the engaged scholarship process applied in a management context.

2. Do research in a familiar context. This enabled the students to focus on the Systems Engineering methods instead of having to spend most of the time understanding the environment. Using students to perform action research is not new. Full-time students often do their final master's work affiliated with a company. These students typically need help in defining relevant problems and more time to understand the context. Having relevant jobs and internships or co-op placements prior to doing research helps students to understand context. This is the case, in our experience, even when the students worked in a domain different from where they are doing research. The Industry Master's students at USN are fully acquainted with both the company and context when they finish their master's paper after three years of work.

3. Hire supervisors with industrial experience that actively guide the students through the research. The working period before starting the master's project serves well to overcome opposing forces between the industrial domain, requiring pragmatic solutions early, and the academic environment, requiring depth and academic rigour. The supervisors are strongly pushing this distinction during the preparation and execution phases of the master projects. This push may explain why more than half of published master papers were clearly able to distinguish action and research. From our results, it seems that the Industry Master's students manage this rather well, but an evaluation from one of the students still characterized their master's project as a "roller coaster experience".

4. Make sure the research results are accessible to the practitioners. In the tradition of experimental learning and action research, the researchers do this by practicing and involving, not only by reporting.

5. Apply Kolb's reflective learning cycle during the research period. Unfortunately, there is limited time, and the students are not always able to apply the full methodology. If the goal is to change the practice, then theory states that action research is well suited to this. We do not have clear evidence that the brief master's projects change practices, but we do know that the companies acquire new knowledge through the students and their research.

6. Apply reflective practice in teaching to enhance learning and change. Recall that the Industry Master's students have been working for at least three years when finalizing their degree. During these three years, they have been simultaneously studying, including a course in reflective practice that teaches them how to reflect on and apply their learnings in the industrial context. Theory states that reflective practice supports action research. Moreover, action research enables students and researchers deep access into their respective companies.

A master's project is the closure of three years of practicing experimental learning with reflective practice as the core and the student's placement within the engineering workplace for most of that time. Even their homework and exams are partly performed in their company. Other, more human-centred or innovative disciplines such as medicine, education, and design have applied situated learning for centuries. They are learning by doing. These fields also actively apply action research as a tool to collect and develop knowledge. Technology disciplines apply situated learning on lower levels, such as with electricians and mechanics. However, at an engineering level, situated learning is not common. For Systems Engineering, having to deal with humans and business in addition to science, the selection of situated learning and action research seems like a natural step. What about other engineers - are they not dealing with people and innovations? We believe that a step towards more situated learning would be beneficial also in other engineering disciplines. 


\section{Embedded Master's Students Conduct Highly Relevant Research Using Industry as Their Laboratory Kristin Falk and Gerrit Muller}

A major contribution of this article is a unique collection of research on engineering practice from within the sponsoring companies. Since the researchers are also the engineers, actively involved in problem solving, they have been able to participate in the engineering practice and collect knowledge that is otherwise not available from the outside. This tacit knowledge is used by colleagues to learn, but it is also available to a broader community and as a way to share learning between companies, domains, and industries. For our case, the Systems Engineering theory originating from space and defense disperses into other industries such as energy and maritime through teaching. The master's students validate the body of knowledge in other industries and identify what is practiced in the industry and what works where. The students must select topics of importance to their companies, which results in relevant research topics. We see a tendency for companies with a high number of Systems Engineering students to change their practices and become aware of the tacit knowledge of their employees. The research papers, written primarily by the students, are to a certain extent also used as curriculum in courses.

\section{Limitations of the current research}

There will be biases in this research. For example, only one of the researchers performed all the review and structuring of the papers. The basis for the review was the written papers, primarily the abstracts, but she also had to go through the conclusions and research methods as well as discussions for most of the papers. The researcher had, prior to this research, read 15 of the papers in depth and been supervisor for five of the students. The researcher spent, on average, about 15 minutes per paper analyzing with a variance of 40 minutes. This was not enough time to read the whole paper. Thus, there will be reflections and methods hidden in the paper that we have not included in this analysis. We did analyze the abstract and conclusions in detail, however. Also, we acknowledge that, although the students are provided with a template, they may reflect and observe in sections other than the abstract or conclusion. Another limitation of the current research is that it is based only on Systems Engineering students working in a small selection of industries. Furthermore, the theory on action research is extensive. We have only tested towards a limited set of publications and ideas.

\section{Further research}

Each master's paper contains only a small contribution to the knowledge of Systems Engineering. If we combine them, the significance will increase. Several of the papers discuss the same methods such as requirements, A3AO, and concept selection. A combined analysis across all the topics should provide a deeper insight into a selection of appropriate methods. The published papers can also be used to investigate details of the separate Systems Engineering practices.

The master's program is still evolving and improving. We are striving to incorporate more of the research into teaching. When it comes to the effect of reflective practice and the form of research, it would be interesting to compare to other groups of students. We would also like to know more about the effect of situated learning, for example, to see if there has been a change of practice.

\section{Conclusion}

This article investigates experiences with action research for master projects over a ten-year period. We reviewed 40 published papers performed by master's students who used the industry-as-laboratory. The papers indicate that the students had a good understanding of the industrial problems they were solving. They identified key triggers for the research and achieved insightful results on the topic of Systems Engineering. We classify $80 \%$ of the papers to be within action research, meaning that the research aims at changing the practice and involves co-learning. Only about half of the papers clearly illustrated the iterative nature of action research, and $75 \%$ used the "plan, act, observe, reflect" cycle. Elements that seem to be hindering the effectiveness of action research include lack of time, communication, and reflections. Elements assisting the effectiveness of action research were strongly related to the students having worked for years in the researching company, but also "proper use of Systems Engineering and research methods."

This article also offers recommendations to industry and universities on how to facilitate participatory action research performed by master's students. In our situation, we embed the students for three years into an industrial setting within the field of Systems Engineering. This familiarizes students with context and enables them to contribute to the action part of research. The problem to solve is thereby important and relevant to industry. The supervisor can facilitate the research by preparing students and by close follow-up of the research process during the master's project. It is crucial that the students report and validate results - only then will the action become research. 


\section{Embedded Master's Students Conduct Highly Relevant Research Using Industry as Their Laboratory Kristin Falk and Gerrit Muller}

\section{Additional Resources}

- Master of Science in Systems Engineering at the University of South-Eastern Norway:

tinyurl.com/y2e6h6za

- Systems Engineering Master Project course material: gaudisite.nl/SEMP.html

- Published Master Project Papers from the Systems Engineering Program: gaudisite.nl/MasterProjectPapers.html

\section{About the Authors}

Kristin Falk is an Associate Professor at University College of Southeastern Norway, where she is responsible for the Systems Engineering Energy track, and fronting research on Systems Engineering. Kristin holds a $\mathrm{PhD}$ in Petroleum Production and a Master's in Industrial Mathematics, both from Norwegian University of Science and Technology. She has worked within the oil and gas industry for 20 years, both with major subsea suppliers and with small startups. She has worked in various roles within engineering and management, cooperating well with multidisciplinary teams. She has successfully taken products from research through qualification and commercialization, and she has led R\&D projects both in industry and academia. Her current research focus is subsea architecture, safety, engineering communication, and innovation within the Systems Engineering framework.

Gerrit Muller, originally from the Netherlands, received his Master's degree in Physics from the University of Amsterdam in 1979. He worked from 1980 until 1997 at Philips Medical Systems as a System Architect, followed by two years at ASML as Manager of Systems Engineering, returning to Philips (Research) in 1999. Since 2003, he has worked as Senior Research Fellow at the Embedded Systems Institute in Eindhoven, focusing on developing system architecture methods and the education of new system architects, receiving his doctorate in 2004. In January 2008, he became full Professor of Systems Engineering at University College of Southeast Norway in Kongsberg, Norway. He continues to work as a Senior Research Fellow at the Embedded Systems Innovations by TNO in Eindhoven in a part-time position.

\section{References}

Beard, C. M., \& Wilson, J. P. 2006. Experiential Learning: A Best Practice Handbook for Educators and Trainers. London: Kogan Page Publishers.

Chestnut, H. 1967. Systems Engineering Methods. New York: John Wiley \& Sons.

Ellström, P.-E. 2007. Knowledge Creation through Interactive Research: A Learning Perspective. Paper presented at the HHS-07 Conference, Jönköping University, Sweden, May 8-11, 2007.

Frank, M. 2014. Towards a 4-D Systems Engineering Cognitive Competency Model. INCOSE International Symposium, 24(1): 617-634. https://doi.org/10.1002/j.2334-5837.2014.tb03171.x

Garousi, V., Petersen, K., \& Ozkan, B. 2016. Challenges and Best Practices in Industry-Academia Collaborations in Software Engineering: A Systematic Literature Review. Information and Software Technology, 79: 106-127. https://doi.org/10.1016/j.infsof.2016.07.006

Goode, H. H., \& Machol, R. E. 1957. System Engineering: An Introduction to the Design of Large-Scale Systems. New York: McGraw-Hill Book Company Inc.

Kolb, D. A. 2014. Experiential Learning: Experience as the Source of Learning and Development. Upper Saddle River, NJ: FT Press.

Koshy, V. 2005. Action Research for Improving Practice: A Practical Guide. London: SAGE.

Lave, J., \& Wenger, E. 1991. Situated Learning: Legitimate Peripheral Participation. Cambridge, UK: Cambridge University Press.

McKinney, D., Arnold, E., \& Sheard, S. 2015. Change Agency for Systems Engineers. INCOSE International Symposium, 25(1): 1209-1231.

https://doi.org/10.1002/j.2334-5837.2015.00125.x

McKinney, D., \& Contractor, S. 2013. Systems Engineering Implications of Neuroscience Discoveries. INCOSE International Symposium, 23(1): 1418-1432.

https://doi.org/10.1002/j.2334-5837.2013.tb03096.x

Muller, G. 2009. Creating an Academic Systems Engineering Group; Bootstrapping Systems Engineering Research. Paper presented at the 7th Annual Conference on Systems Engineering Research, Loughborough University, UK, April 20-23, 2009.

Muller, G. 2012. Validation of Systems Engineering Methods and Techniques in Industry. Procedia Computer Science, 8: 321-326. https://doi.org/10.1016/j.procs.2012.01.067

Muller, G. 2013. Systems Engineering Research Methods. Procedia Computer Science, 16: 1092-1101. https://doi.org/10.1016/j.procs.2013.01.115

Muller, G. 2015. Reflective Practice to Connect Theory and Practice; Working and Studying Concurrently. Procedia Computer Science, 44: 679-688. https://doi.org/10.1016/j.procs.2015.03.008

Muller, G., \& Bonnema, G. M. 2013. Teaching Systems Engineering to Undergraduates; Experiences and Considerations. INCOSE International Symposium, 23(1): 98-111. 


\section{Embedded Master's Students Conduct Highly Relevant Research Using Industry as Their Laboratory Kristin Falk and Gerrit Muller}

Muller, G., \& Falk, K. 2018. What Can (Systems of) Systems Engineering Contribute to Oil and Gas? An illustration with Case Studies from Subsea. In Proceedings of the 13th Annual Conference on System of Systems Engineering (SoSE): 629-635.

Muller, G., \& Heemels, W. M. 2007. Five Years of Multi-Disciplinary Academic and Industrial Research: Lessons Learned. In Proceedings of the 5th Annual Conference on Systems Engineering Research (CSER), Hoboken, NJ, March 14-16, 2007.

Nilsen, M. A., Falk, K., \& Haugen, T. A. 2018. Reducing Project Cost Growth through Early Implementation of Interface Management. INCOSE International Symposium, 28(1): 96-114.

O'Brien, R. 2001. Um exame da abordagem metodológica da pesquisa ação [An Overview of the Methodological Approach of Action Research]. In R. Richardson (Ed.), Teoria e Prática da Pesquisa Ação [Theory and Practice of Action Research]. João Pessoa, Brazil: Universidade Federal da Paraíba.

Potts, C. 1993. Software-Engineering Research Revisited. IEEE Software, 10(5):19-28.

Research-Methodology.net. 2018. Action Research. ResearchMethodology.net. Accessed November 25, 2018: https://research-methodology.net/research-methods/actionresearch/
Saunders, M., Lewis, P., \& Thornhill, A. 2012. Research Methods for Business Students (6th ed). Harlow, UK: Pearson.

Tranøy, E., \& Muller, G. 2014. Reduction of Late Design Changes through Early Phase Need Analysis. INCOSE International Symposium, 24(1): 570-582.

Tripp, D. 2005. Action Research: A Methodological Introduction. Educacao e pesquisa, 31(3): 443-466. http://dx.doi.org/10.1590/S1517-97022005000300009

Valerdi, R., Brown, S., \& Muller, G. 2010. Towards a Framework of Research Methodology Choices in Systems Engineering. In Proceedings of the 8th Annual Conference on Systems Engineering Research, Hoboken, NJ, March 17-19, 2010.

Van de Ven, A. H. 2007. Engaged Scholarship: A Guide for Organizational and Social Research. Oxford: Oxford University Press.

Vygotsky, L. S. 1978. Mind in Society: The Development of Higher Mental Processes. Cambridge, MA: Harvard University Press.

Vygotsky, L. S. 1986. Thought and Language. (A. Kozulin, Trans. and Ed.). Cambridge, MA: The MIT Press. 


\section{Embedded Master's Students Conduct Highly Relevant Research Using Industry as Their Laboratory Kristin Falk and Gerrit Muller}

Appendix 1. Papers published by the Industry Master's students

\begin{tabular}{|c|c|c|c|c|c|}
\hline \# & Student Name & Year & Problem to Solve & Systems Engineering Topic & Industrial Domain \\
\hline 1 & Marianne I. Drotninghaug & 2010 & Logistics & Value of Systems Engineering & Manufacturing \\
\hline 2 & Even Engebakken & 2010 & Safety & Conceptual modelling & Manufacturing \\
\hline 3 & Jorn Breivoll & 2010 & $\begin{array}{l}\text { Cost and schedule } \\
\text { overrun }\end{array}$ & Trade study & Maritime \\
\hline 4 & Andreas Rasmussen & 2010 & Risk in early phase & Risk assessment & Maritime \\
\hline 5 & Volker Heierhoff & 2011 & $\begin{array}{l}\text { Resource } \\
\text { management }\end{array}$ & $\begin{array}{l}\text { Enterprise resource } \\
\text { management (ERP) }\end{array}$ & Energy \\
\hline 6 & $\begin{array}{l}\text { Dag Jostein Klever \& Halvard } \\
\text { H. Bjørnsen }\end{array}$ & 2011 & $\begin{array}{l}\text { Competitive } \\
\text { advantage }\end{array}$ & Concept selection & Energy \\
\hline 7 & Levi Vigdal & 2011 & Risk & Conceptual modelling & Energy \\
\hline 8 & Jan Magnus Røkke & 2011 & $\begin{array}{l}\text { Avoid late design } \\
\text { changes and rework }\end{array}$ & Requirements & Energy \\
\hline 9 & Elisabeth Hansen & 2012 & Efficiency in design & Lean & Automotive \\
\hline 10 & Rasmus Wibe Rypdal & 2012 & $\begin{array}{l}\text { Competitive } \\
\text { advantage }\end{array}$ & Project management & Manufacturing \\
\hline 11 & Bjørnar Wiulsrød & 2012 & Cost & A3AO & Maritime \\
\hline 12 & Jan Ove Mjånes & 2013 & Project execution & Lifecycle management & Energy \\
\hline 13 & Asgeir Øvergaard & 2013 & Cost & Automated software testing & Maritime \\
\hline 14 & Vickram Singh & 2013 & $\begin{array}{l}\text { Cost of late design } \\
\text { changes }\end{array}$ & A3AO & Energy \\
\hline 15 & Arne Kristian Bye & 2014 & $\begin{array}{l}\text { System } \\
\text { optimization }\end{array}$ & Concept election & Energy \\
\hline 16 & Eldar Tranøy & 2014 & Cost and time & Needs analysis & Energy \\
\hline 17 & Linda Lønmo & 2014 & Cost and time & Concept selection & Energy \\
\hline 18 & Anders Fuglesteg Nilsen & 2014 & $\begin{array}{l}\text { Customer } \\
\text { satisfaction }\end{array}$ & A3AO & Consultancy \\
\hline 19 & Bjørn Stalsberg & 2014 & $\begin{array}{l}\text { Customer } \\
\text { satisfaction }\end{array}$ & Modelling tools & Manufacturing \\
\hline 20 & Halvor Eide & 2016 & Cost and time & Trade study & Energy \\
\hline
\end{tabular}




\section{Embedded Master's Students Conduct Highly Relevant Research Using Industry as Their Laboratory Kristin Falk and Gerrit Muller}

Appendix 1 (continued). Papers published by the Industry Master's students

\begin{tabular}{|c|c|c|c|c|c|}
\hline$\#$ & Student Name & Year & Problem to Solve & Systems Engineering Topic & Industrial Domain \\
\hline 21 & Thomas Henanger & 2016 & $\begin{array}{l}\text { Complexity in } \\
\text { installation }\end{array}$ & Conceptual modelling & Energy \\
\hline 22 & Arne Rugaas & 2016 & $\begin{array}{l}\text { Cost due to late } \\
\text { design changes }\end{array}$ & Knowledge management & Energy \\
\hline 23 & Peter Callister & 2016 & Technical risk & Systems integration & Energy \\
\hline 24 & Herman Solli & 2016 & Cost & Concept selection & Energy \\
\hline 25 & Kok Yi Damien Wee & 2016 & Quality and cost & Requirements & Energy \\
\hline 26 & Alexander Svendsen & 2016 & Quality & A3 & Energy \\
\hline 27 & Arne Goderstad & 2016 & Quality & Trade study & Defense \\
\hline 28 & $\begin{array}{l}\text { Aksel Botne Sandberg \& Eirik } \\
\text { Klementsen (Outside of the } \\
\text { Industry Master's program) }\end{array}$ & 2016 & Commercialization & PESTEL/Porter & New Energy \\
\hline 29 & Lars Petter Bryn & 2017 & Cost and robustness & Conceptual modelling & Energy \\
\hline 30 & Simen Bergli & 2017 & Cost and quality & Qualification & Energy \\
\hline 31 & Anders Roe Nykaas & 2017 & $\begin{array}{l}\text { Complexity in } \\
\text { installation }\end{array}$ & Autonomous & Energy \\
\hline 32 & Simon Aasheim & 2017 & $\begin{array}{l}\text { Cost of late design } \\
\text { changes }\end{array}$ & Requirements & Energy \\
\hline 33 & Kristian Frøvold & 2017 & $\begin{array}{l}\text { Attractive } \\
\text { product/system }\end{array}$ & $\mathrm{A} 3 \mathrm{AO}$ & Maritime \\
\hline 34 & Magnus André Nilsen & 2018 & Cost and time & Interface management & Energy \\
\hline 35 & Sindre Løndal & 2018 & $\begin{array}{l}\text { Cost and time of } \\
\text { engineering }\end{array}$ & $\mathrm{A} 3 \mathrm{AO}$ & Energy \\
\hline 36 & Ole Kaare Ulsvik & 2018 & $\begin{array}{l}\text { Time and cost of } \\
\text { engineering }\end{array}$ & Standardization & Energy \\
\hline 37 & Kjersti Bakke & 2018 & Literature survey & Technology readiness levels & None \\
\hline 38 & Christoffer Jimmy Røsegg & 2018 & $\begin{array}{l}\text { Time and cost of } \\
\text { testing and } \\
\text { integration }\end{array}$ & Verification & Energy \\
\hline 39 & Maximiliano Moraga & 2018 & Legacy software & Conceptual modelling & Manufacturing \\
\hline 40 & Anders Viken & 2018 & $\begin{array}{l}\text { Time of } \\
\text { commissioning }\end{array}$ & A3AO & Maritime \\
\hline
\end{tabular}




\section{Embedded Master's Students Conduct Highly Relevant Research Using Industry as Their Laboratory Kristin Falk and Gerrit Muller}

\section{References for Appendix 1}

1. Drotninghaug, M. I., Muller, G., \& Pennotti, M. 2009. The Value of Systems Engineering Tools for Understanding and Optimizing the Flow and Storage of Finished Products in a Manganese Production Facility. EUSEC 2010: Stockholm.

https://www.gaudisite.nl/EUSEC2010_DrotninghaugEtAl_SEatManganeseProduction.pdf

2. Engebakken, E., Muller, G., \& Pennotti, M. 2010. Supporting the System Architect: Model-Assisted Communication. Systems Research Forum, 4(02): 173-188. https://www.gaudisite.nl/SRF2010-2_Engebakken_Muller_Pennotti_Modeling.pdf

3. Breivoll, J., \& Muller, G. 2010. Change Impact Analysis-A Case Study. In Proceedings of the 8th Conference on Systems Engineering Research: 668-677. https://www.gaudisite.nl/CSER2010_BreivollMullerPennotti_changeImpact.pdf

4. Rasmussen, A., Maritime, K., Muller, G., \& P Pennotti, M. 2010. Causal Loop Based Change Propagation and Risk Assessment. EUSEC 2010. Stockholm. https://www.gaudisite.nl/EUSEC2010_RasmussenEtAl_CausalLoop.pdf

5. Heierhoff, V., Arntzen, A. A. B., \& Muller, G. 2011. A Training Model for Successful Implementation of Enterprise Resource Planning. International Journal of Information and Communication Engineering, 5(12): 505-511.

https://www.gaudisite.nl/WASET2011_HeierhoffEtAl_ERPtraining.pdf

6. Muller, G., Klever, D. G., Bjørnsen, H. H., \& Pennotti, M. 2011. Researching the Application of Pugh Matrix in the Sub-Sea Equipment Industry. In Proceedings of the 9th Annual Conference on Systems Engineering Research (CSER).

https://www.gaudisite.nl/CSER2011_MullerEtAl_ResearchingPughMatrix.pdf

7. Vigdal, L. A. B., Muller, G., \& Pennotti, M. 2011. How Applying Models in Work Group Sessions Can Help to Retrieve Information for Making FTA and FMECA Analysis. INCOSE International Symposium, 21(1): 14-27.

https://www.gaudisite.nl/INCOSE2011_Vigdal_FTAandFMECAanalysis.pdf

8. Røkke, J. M., Muller, G., \& Pennotti, M. 2011. Requirement Elicitation and Validation by Prototyping and Demonstrators: User Interface Development in the Oil and Gas Industry. Systems Research Forum, 5(02): 89-108.

https://www.gaudisite.nl/SRF2011-2_Rokke_Muller_Pennotti_RequirementElicitation.pdf

9. Hansen, E., \& Muller, G. 2012. Set-Based Design-The Lean Tool that Eludes Us; Pitfalls in Implementing Set-Based Design in Kongsberg Automotive. INCOSE International Symposium, 22(1): 1603-1618.

https://www.gaudisite.nl/INCOSE2012_Hansen_Muller_SetBasedDesign.pdf

10. Rypdal, R. W., Muller, G., \& Pennotti, M. 2012. Developing the Modeling Recommendation Matrix: Model-Assisted Communication at Volvo Aero. INCOSE International Symposium, 22(1): 1870-1883. https://www.gaudisite.nl/INCOSE2012_RypdalEtAl_ModelMaker.pdf

11. Wiulsrød, B., Muller, G., \& Pennotti, M. 2012. Architecting Diesel Engine Control System Using A3 Architecture Overview. INCOSE International Symposium, 22(1): 1791-1805. https://www.gaudisite.nl/INCOSE2012_Wiulsr\%C3\%B8dEtAl_DieselEngineA3.pdf

12. Mjånes, J. O., Haskins, C., \& Piciaccia, L. A. 2013. Closing the Loop for Lifecycle Product Management in Norwegian Subsea Systems. INCOSE International Symposium, 23(1): 490-501.https://www.gaudisite.nl/INCOSE2013_Mj\%C3\%A5nesEtAl_SEprocess.pdf

13. Øvergaard, A., \& Muller, G. 2013.System Verification by Automatic Testing. INCOSE International Symposium, $23(1)$ : 356-367. https://www.gaudisite.nl/INCOSE2013_\%C3\%98vergaard_Muller_AutomatedTesting.pdf

14. Singh, V., \& Muller, G. 2013. Knowledge Capture, Cross Boundary Communication and Early Validation with Dynamic A3 Architectures. INCOSE International Symposium, 23(1): 84-97. https://www.gaudisite.nl/INCOSE2013_Singh_Muller_DynamicA3.pdf

15. Bye, A. K., \& Piciaccia, L. A. 2014. System Engineering Applied to Concept Design Optimization of Subsea Coolers. INCOSE International Symposium, 24(1): 599-616. https://www.gaudisite.nl/INCOSE2014_Bye_Piciaccia_SubseaCoolers.pdf

16. Tranøy, E., \& Muller, G. 2014. Reduction of Late Design Changes Through Early Phase Need Analysis. INCOSE International Symposium, 24(1): 570-582. https://www.gaudisite.nl/INCOSE2014_Tran\%C3\%B8y_Muller_ReductionOfLateDesignChanges.pdf

17. Lønmo, L., \& Muller, G. 2014. Concept Selection-Applying Pugh Matrices in the Subsea Processing Domain. INCOSE International Symposium, 24(1): 583-598. https://www.gaudisite.nl/INCOSE2014_Lonmo_Muller_ConceptSelection.pdf

18. Nilsen, A. F., \& Muller, G. 2014. 1.2. 1 Use Cases and Non-functional Requirements Presented in Compact System Description A3s. INCOSE International Symposium, 24(1): 1-15. https://www.gaudisite.nl/INCOSE2014_Nilsen_Muller_NFRinA3.pdf

19. Stalsberg, B., \& Muller, G. 2014. Increasing the Value of Model-Assisted Communication: Modeling for Understanding, Exploration and Verification in Production Line Design Projects. INCOSE International Symposium, 24(1): 827-842.

https://www.gaudisite.nl/INCOSE2014_Stalsberg_Muller_ModelingProductionLine.pdf

20. Eide, H. M., \& Haskins, C. 2016. Trade Study of Alternative Controls and Power Distribution Architecture in Subsea Processing. INCOSE International Symposium, 26(1): 2148-2163. https://www.gaudisite.nl/INCOSE2016_Eide_Haskins_Control.pdf

21. Henanger, T., Muller, G., \& Picacia, L. 2016. Managing Installation Tolerances through System Modeling and Tolerance Budgeting. INCOSE International Symposium, 26(1): 1176-1191. https://www.gaudisite.nl/INCOSE2016_HenangerEtAl_Tolerances.pdf

22. Rugaas, A. K., \& Zhao, Y. Y. 2016. Knowledge Roadmap across Design and Engineering: An User-Centric Didactic Approach. IEEE International Conference on Industrial Engineering and Engineering Management (IEEM): 686-690. https://doi.org/10.1109/IEEM.2016.7797963

timreview.ca 


\section{Embedded Master's Students Conduct Highly Relevant Research Using Industry as Their Laboratory Kristin Falk and Gerrit Muller}

23. Callister, P. S., \& Andersson, J. 2016. Evaluation of System Integration and Qualification Strategies Using the Technical Debt Metaphor; A Case Study in Subsea System Development. INCOSE International Symposium, 26(1): 1016-1028.

https://www.gaudisite.nl/INCOSE2016_Callister_Andersson_SMARTtechnicalDebt.pdf

24. Solli, H., \& Muller, G. 2016. Evaluation of Illustrative ConOps and Decision Matrix as Tools in Concept Selection. INCOSE International Symposium, 26(1): 2361-2375. https://www.gaudisite.nl/INCOSE2016_Solli_Muller_VisualConOps.pdf

25. Damien Wee, K. Y., \& Muller, G. 2016. Evaluating the Effectiveness of Applying a Requirements Management System for a Subsea Oil and Gas Workover System. INCOSE International Symposium, 26(1): 2346-2360. https://www.gaudisite.nl/INCOSE2016_Wee_Muller_Requirements.pdf

26. Svendsen, A., \& Haskins, C. 2016. Applying A3 Problem Resolution to New System Design to Improve Performance and Reduce Rework. INCOSE International Symposium, 26(1): 1161-1175. https://www.gaudisite.nl/INCOSE2016_Svendsen_Haskins_A3problemResolution.pdf

27. Goderstad, A. B., \& Haskins, C. 2016. Understanding Mission Objectives and Priorities with QFD. INCOSE International Symposium, 26(1): 283-299. https://www.gaudisite.nl/INCOSE2016_Goderstad_Haskins_QFD.pdf

28. Sandberg, A., Klementsen, E., Muller, G., de Andres, A., \& Maillet, J. 2016. Critical Factors Influencing Viability of Wave Energy Converters in OffGrid Luxury Resorts and Small Utilities. Sustainability, 8(12): 1274. https://doi.org/10.3390/su8121274

29. Bryn, L. P., \& Muller, G. 2017. Evolving Tolerance Management for Increased Robustness of Subsea Installation Operations. INCOSE International Symposium, 27(1): 242-256. https://www.gaudisite.nl/INCOSE2017_Bryn_MullerToleranceManagement.pdf

30. Bergli, S., \& Falk, K. 2017. Cause and Impact Analysis of Cost and Schedule Overruns in Subsea Oil and Gas Projects-A Supplier's Perspective. INCOSE International Symposium, 27(1): 309-321. https://www.gaudisite.nl/INCOSE2017_Bergli_Falk_CostAnalysis.pdf

31. Nykaas, A. R., \& Zhao, Y. Y. 2017. A Context-Enabled Systems Development Method: The Case of Semi-Autonomous Remotely Operated Vehicles in an Arctic Environment. INCOSE International Symposium, 27(1): 229-241.

https://www.gaudisite.nl/INCOSE2017_Nykaas_Zhao_ROV.pdf

32. Aasheim, S., \& Zhao, Y. Y. 2017. Developing the Stakeholder Requirements Definition Process—A Journey of Customization. 12th System of Systems Engineering Conference (SoSE): 1-6. https://www.gaudisite.nl/SOSE2017_Aasheim_Zhao_RequirementsDefinition.pdf

33. Frøvold, K., Muller, G., \& Pennotti, M. 2017. Applying A3 Reports for Early Validation and Optimization of Stakeholder Communication in Development Projects. INCOSE International Symposium, 27(1): 322-338. https://www.gaudisite.nl/INCOSE2017_Frovold_A3.pdf

34. Nilsen, M. A., Falk, K., \& Haugen, T. A. 2018. Reducing Project Cost Growth Through Early Implementation of Interface Management. INCOSE International Symposium, 28(1): 96-114. https://www.gaudisite.nl/INCOSE2018_Nilsen_Falk_InterfaceManagement.pdf

35. Løndal, S., \& Falk, K. 2018. Implementation of A3 Architectural Overviews in Lean Product Development Teams; A Case Study in the Subsea Industry. INCOSE International Symposium, 28(1): 1737-1752. https://www.gaudisite.nl/INCOSE2018_Londal_Falk_A3subsea.pdf

36. Ulsvik, O. K., \& Falk, K. 2018. Developing a Configure-to-Order Product in the Subsea Oil and Gas Domain. INCOSE International Symposium, 28(1): 209-225. https://www.gaudisite.nl/INCOSE2018_Ulsvik_Falk_ConfigureToOrder.pdf

37. Bakke, K., \& Haskins, C. 2018. Use of TRL in the Systems Engineering Toolbox. INCOSE International Symposium, 28(1): 587-601. https://www.gaudisite.nl/INCOSE2018_Bakke_Haskins_TRL.pdf

38. Røsegg, C. J., \& Falk, K. 2018. The Importance of Project Management in the System Integration, Verification and Validation Process. INCOSE International Symposium, 28(1): 226-244. https://www.gaudisite.nl/INCOSE2018_Rosegg_Falk_PMinVV.pdf

39. Moraga, M., \& Zhao, Y. Y. 2018. Reverse Engineering a Legacy Software in a Complex System: A Systems Engineering Approach. INCOSE International Symposium, 28(1): 1250-1264. https://www.gaudisite.nl/INCOSE2018_Moraga_Yang_LegacySoftware.pdf

40. Viken, A., \& Muller, G. 2018. Creating and Applying A3 Architecture Overviews: A Case Study in Software Development. INCOSE International Symposium, 28(1): 378-391. https://www.gaudisite.nl/INCOSE2018_Viken_MullerA3.pdf

The following published papers were not included in the analysis because they were not readily available at the time of the analysis:

- Bøhn, A.H. \& Arntzen Bechina, A.A. 2015. A Generic A3 Framework for Sharing Knowledge in a Systems Engineering Context. Society for Design and Process Science, 20: 334-341.

- Haugen, J. A., \& Arntzen Bechina, A. A. 2016. An Investigation of Cost Based Framework for Documentation Reuse. Society for Design and Process Science, 21: 18-24.

- Simonsen, J.Ø.G \& Arntzen Bechina, A. A. 2014. A Model of Knowledge Sharing Fostering the Learning Capability - A Case Study within the Aerospace Industry. Society for Design and Process Science, 19: 447-455.

Citation: Falk, K., \& Muller, G. 2019. Embedded Master's Students Conduct Highly Relevant Research Using Industry as Their Laboratory. Technology Innovation Management Review, 9(5): 54-73. http://doi.org/10.22215/timreview/1241

Keywords: participatory research, action research, experimental learning, situated learning, Systems Engineering, master's students, knowledge transfer, master project, lessons learned, industrial knowledge, industry as laboratory, innovations, systems of systems, energy 


\section{Academic Affiliations and Funding Acknowledgements}
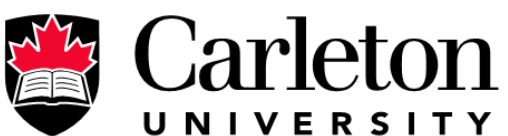

U N I V E R S I T Y

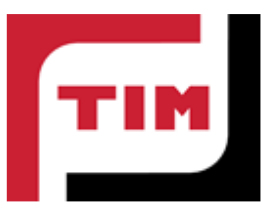

Technology Innovation Management (TIM; timprogram.ca) is an international master's level program at Carleton University in Ottawa, Canada. It leads to a Master of Applied Science (M.A.Sc.) degree, a Master of Engineering (M.Eng.) degree, or a Master of Entrepreneurship (M.Ent.) degree. The objective of this program is to train aspiring entrepreneurs on creating wealth at the early stages of company or opportunity lifecycles.

- The TIM Review is published in association with and receives partial funding from the TIM program. 